\title{
Cytokines and liver diseases
}

\author{
Herbert Tilg MD
}

\begin{abstract}
$\mathrm{H}$ Tilg. Cytokines and liver diseases. Can J Gastroenterol 2001;15(10):661-668. Cytokines are pleiotropic peptides produced by virtually every nucleated cell in the body. In most tissues, including the liver, constitutive production of cytokines is absent or minimal. There is increasing evidence that several cytokines mediate hepatic inflammation, apoptosis and necrosis of liver cells, cholestasis and fibrosis. Interestingly, the same mediators also mediate the regeneration of liver tissue after injury. Among the various cytokines, the proinflammatory cytokine tumour necrosis factor-alpha (TNF- $\alpha$ ) has emerged as a key factor in various aspects of liver disease, such as cachexia and/or cholestasis. Thus, antagonism of TNF- $\alpha$ and other injuryrelated cytokines in liver diseases merits evaluation as a treatment of these diseases. However, because the same cytokines are also necessary for the regeneration of the tissue after the liver has been injured, inhibition of these mediators might impair hepatic recovery. The near future will bring the exiting clinical challenge of testing new anticytokine strategies in various liver diseases.
\end{abstract}

Key Words: Liver disease; Cytokines; TNF- $\alpha$; Tumour necrosis factor-alpha

\section{Cytokines et hépatopathies}

RÉSUMÉ : Les cytokines sont des peptides pléïotropes, produits par presque toutes les cellules nucléées de l'organisme. Dans la plupart des tissus, y compris le foie, la production constitutive de cytokines est minimale, voire absente. De plus en plus de données mettent en évidence le fait que plusieurs cytokines agissent comme médiateurs dans l'inflammation du foie, l'apoptose et la nécrose des cellules hépatiques, la cholestase et la fibrose. Point intéressant à souligner, ces mêmes médiateurs participent aussi à la régénération du tissu hépatique après sa lésion. Parmi les nombreuses cytokines, le facteur de nécrose tumorale alpha (TNF- $\alpha$ ) pro-inflammatoire semble jouer un rôle clé dans diverses maladies du foie, par exemple la cachexie ou la cholestase. Aussi les antagonistes du TNF- $\alpha$ et d'autres cytokines liées à l'apparition de lésions dans les hépatopathies méritent-ils notre attention pour traiter ces maladies. Toutefois, comme ces mêmes cytokines interviennent pour régénérer le tissu hépatique après sa lésion, l'inhibition de ces médiateurs pourrait entraver le processus de réparation. Bientôt, nous ferons face au défi clinique de vérifier l'efficacité de nouveaux traitements « anticytokines » dans diverses maladies du foie.
C

yytokines are regulatory peptides that can be produced by virtually every nucleated cell type in the body, such as leukocytes, dendritic cells, epithelial cells, hepatocytes, fibroblasts and many others $(1,2)$. Constitutive production of cytokines is absent or low. Most cytokines, however, are released by activated cells and thereby function as key mediators in immune and inflammatory disorders in an autocrine, paracrine or endocrine manner. This growing

Department of Medicine, Division of Gastroenterology and Hepatology, University Hospital Innsbruck, Innsbruck, Austria

Correspondence and reprints: Dr Herbert Tilg, Department of Medicine, Division of Gastroenterology and Hepatology, University Hospital Innsbruck, Anichstrasse 35, 6020 Innsbruck, Austria. Telephone +43-512-504-3255, fax +43-512-504-3391, e-mail Herbert.Tilg@uibk.ac.at

Received for publication January 6, 2000. Accepted January 24, 2001 
TABLE 1

\section{Role of cytokines in liver diseases}

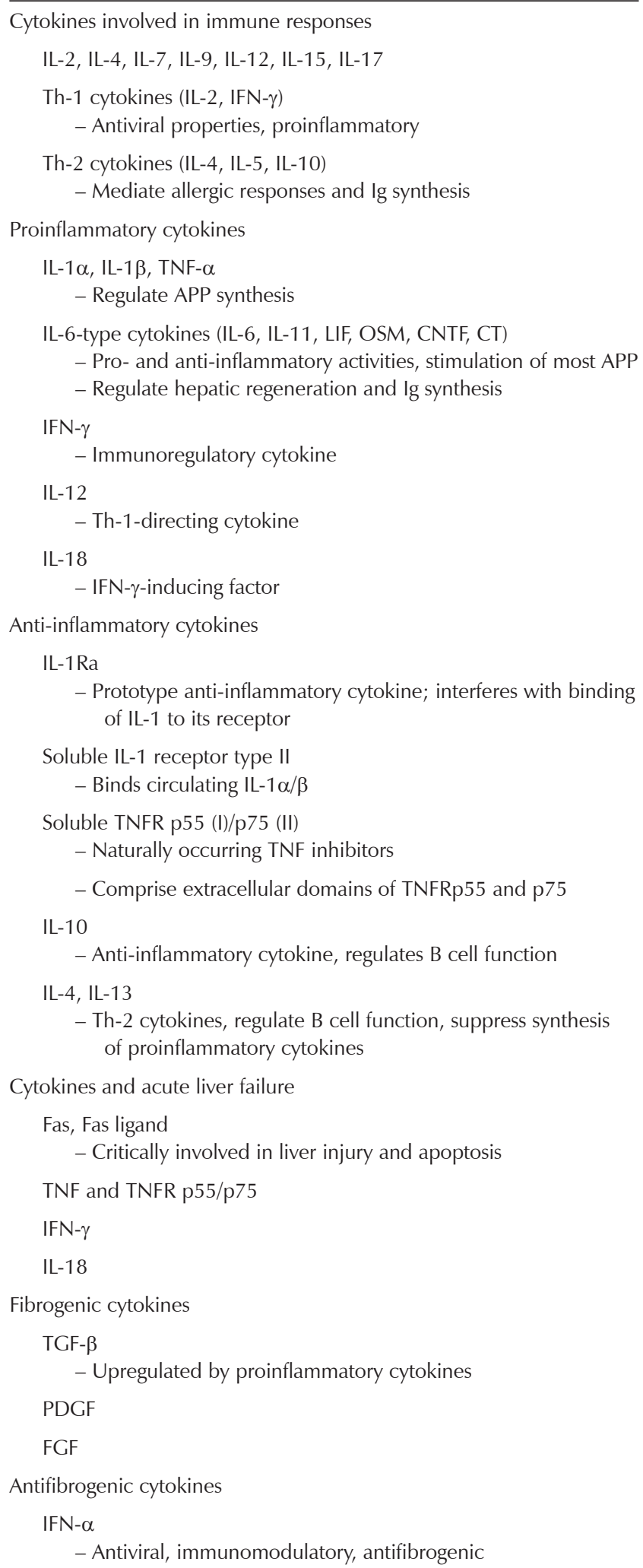

$\overline{A P P}$ Acute phase proteins; CNTF Ciliary neurotrophic factor; CT Cardiotrophin; FGF Fibroblast growth factor; Ig Immunoglobulin; IFN Interferon; IL Interleukin; IL-1Ra IL-1 receptor antagonist; LIF Leukemia inhibitory factor; OSM Oncostatin M; PDGF Platelet-derived growth factor; TGF Transforming growth factor; Th T helper cell; TNF Tumour necrosis factor; TNFRs TNF receptors group of pleiotropic peptides includes interleukins (IL), the tumour necrosis factor (TNF) family of cytokines, IL-6 and IL-6-related cytokines (oncostatin M, ciliary neurotrophic factor, cardiotrophin, leukemia inhibitory factor), interferons (IFNs), chemokines such as IL-8, transforming growth factor-beta (TGF- $\beta$ ) and others. There is increasing evidence supporting a major role for several cytokines in various aspects of liver diseases (Table 1). With respect to acute and chronic liver diseases, the net biological response of cytokines involved in inflammation and fibrosis may affect the outcome of these diseases. This review describes current concepts and roles of cytokines in the pathophysiology of liver diseases and possible therapeutic cytokinemodulating strategies.

\section{EXPERIMENTAL EVIDENCE FOR A ROLE OF CYTOKINES IN LIVER DISEASES AND LIVER REGENERATION}

Animal models of hepatic injury and inflammation: Cytokines are involved in several animal models of liver failure. The prototype models showing an involvement of cytokines in acute liver failure use injection of endotoxin in galactosamine-sensitized animals and injection of concanavalin A $(3,4)$. Inflammatory cellular infiltration (neutrophils, $\mathrm{T}$ cells) is a typical feature in these models. In both models, the proinflammatory cytokine TNF- $\alpha$ is the central mediator of apoptotic and necrotic liver damage. Antiinflammatory strategies such as prior administration of antiTNF antibodies, soluble TNF receptors, IL-6 or IL-10 have prevented toxicity in both models (3-5). Whereas in most animal models that use bacterial toxins, liver damage is dependent on TNF and the presence of T cells (6), in a murine cytomegalovirus model of hepatitis, toxicity is independent of natural killer and T cells (7).

Despite their involvement in acute liver damage, cytokines are also involved in a more chronic model of liver inflammation and fibrosis. IL-10 gene-knockout mice treated with carbon tetrachloride reveal significantly more severe fibrosis and exhibit higher hepatic TNF- $\alpha$ levels than wild-type control mice (8). Therefore, IL-10 synthesized during the course of liver inflammation and fibrosis may modulate Kupffer cell actions, and influence subsequent progression of fibrosis.

Role of the Fas/Fas ligand pathway in hepatitis and liver failure: Death receptors are members of the TNF/nerve growth factor superfamily of receptors. Death receptors include Fas, TNF receptors I (p55) and II (p75), and others. Cells rapidly undergo apoptotic cell death upon Fas engagement with Fas/Fas ligand (FasL) or agonistic antibodies (9).

Besides TNF, the Fas pathway is an independent trigger of murine apoptotic liver failure and is involved in liver disease. Hepatocytes express Fas constitutively on their surface, and Fas stimulation in mice has been shown to induce fulminant hepatic failure within hours (10). It has been shown that liver failure and liver cell damage in acute Wilson's disease involve Fas-mediated apoptosis (11). 
Various other hepatotoxic substances are also able to induce apoptosis, including ethanol, toxins and bile salts. In alcoholic cirrhosis, chronic viral hepatitis B and C, and fulminant hepatic failure of different etiology, upregulation of the Fas/FasL system has been demonstrated (11).

It is still unclear which cytokine pathway reflects the most proximal step in liver damage. Recent data suggest that IL-18, another proinflammatory cytokine that has the ability to induce IFN- $\gamma$ production and synthesis of FasL, accounts for both TNF- $\alpha$ and FasL-mediated hepatotoxic pathways in endotoxin-induced liver injury in mice (12). Neutralization of IL-18 in this model prevents liver damage and synthesis of IFN- $\gamma$, TNF- $\alpha$ and FasL. Therefore, different cytokine pathways, including IL-18, TNF- $\alpha$ and FasL, may be involved in liver injury.

Cytokines and hepatic regeneration: Whereas TNF is a key mediator of liver damage, it recently was shown that this cytokine is also critically involved in hepatic regeneration. After chemical liver injury, anti-TNF antibodies inhibit regeneration, and in TNF receptor type I knockout mice, liver regeneration is impaired $(13,14)$. Interestingly, in this model, injection of IL-6 compensates for this deficiency, suggesting that this mediator is even more critical for hepatic regeneration (14). Mice with targeted disruption of the IL- 6 gene show impaired liver regeneration after partial hepatectomy, which is characterized by liver failure (15). Treatment of IL-6-deficient mice with a single preoperative dose of IL-6 prevented liver damage completely (15).

Hepatocyte growth factor (HGF), first identified as the most potent mitogen for hepatocytes, has been shown to have multiple biological properties in the liver, including mitogenic, antifibrotic and anti-apoptotic activities. HGF promotes liver regeneration, with rapid improvement of hyperbilirubinemia in partially hepatectomized cholestatic rats (16). Portal branch ligation with a continuous HGF supply allows extensive hepatectomy in cirrhotic rats, supporting the evidence that HGF has an important role in hepatic regeneration (17). The factors involved in liver regeneration, such as TNF- $\alpha$, IL- 6 and HGF, have been demonstrated to activate similar signalling pathways and transcription factors such as signal transducers and activators of transcription 3 (18). Thus, some cytokines involved in liver damage, eg, TNF- $\alpha$, are also critically involved in liver regeneration.

\section{CLINICAL STUDIES OF ENDOTOXIN AND CYTOKINES IN HEPATIC INFLAMMATION}

Endotoxin and liver disease: Endotoxin is one of the most powerful activators of the cytokine cascade $(1,2)$. Several studies have demonstrated increased circulating levels of endotoxin in liver cirrhosis $(19,20)$. Endotoxin, a constituent of the cell wall of Gram-negative bacilli, can be absorbed under normal circumstances from the gastrointestinal tract into the portal vein system and then undergoes clearance by the hepatic reticuloendothelial system $(19,20)$. In patients with acute and chronic liver disease, an impairment of the reticuloendothelial system and/or the presence of portosystemic shunts may lead, in the absence of sepsis, to the release of endotoxin into the systemic circulation. Gastrointestinal bleeding, hypotension and alcohol intake can increase endotoxin absorption (19-21). Endotoxin levels also correlate with the severity of hepatic insufficiency and may be persistently elevated $(19,21)$. It has been suggested that bacterial infections and endotoxemia may be important triggers of variceal bleeding in cirrhosis (21). Endotoxemia has been proven to be a powerful activator of clotting and fibrinolysis in liver cirrhosis $(19,22)$.

It is not known how tolerance may occur in patients with continuous endotoxemia. In a rat model of chronic administration of endotoxin and ethanol, it has been demonstrated that tolerance may be mediated by downregulation of the hepatic expression of the CD14 endotoxin receptor and the lipopolysaccharide-binding protein paralleled by enhanced hepatic synthesis of anti-inflammatory cytokines (23). Despite the potential development of partial tolerance toward endotoxin, overall cirrhosis-associated endotoxemia may cause continuous activation not only of the clotting, but also of the cytokine cascade, as discussed in the next paragraph.

Evidence for impaired cytokine synthesis in liver diseases: Either hepatic or extrahepatic cells are sources for cytokine synthesis in liver diseases. Most cell types in the liver such as Kupffer cells, hepatocytes, stellate cells and lymphocytes are able to either synthesize or respond to cytokines. Depending on the cause of liver disease, several infectious, noninfectious and metabolic agents may act as primary stimuli for cytokine production (1). In advanced stages of liver diseases, endotoxin may play a central role in the perpetuation of this process.

Increased serum/plasma concentrations of cytokines in liver diseases: Although the pathogenetic role of circulating cytokines in the development of hepatic inflammation is not clear, studies evaluating circulating cytokines are of importance because they give insight into systemic disease manifestations linked to these mediators. Initial reports focused on studying circulating cytokines in acute liver diseases. The first report showing increased circulating levels of TNF and IL-1 in acute liver failure was published more than 10 years ago (24). Subsequent studies showed similar results, and especially focused on the balance of pro- and anti-inflammatory cytokines. High cytokine levels observed in patients with acute liver failure and the significantly elevated IL-1 receptor antagonist (IL-1Ra)/IL-1 $\beta$ ratio in the patients who survived compared with those who did not suggest the possible therapeutic use of cytokine antagonists for the control of this disease (25).

Elevated circulating levels of TNF- $\alpha$, IL-1 $\beta$, IL- 6 and IFN- $\gamma$ have been described in most patients with chronic liver disease irrespective of the etiology of liver disease (26-29). In general, patients with cirrhosis demonstrate higher circulating cytokine levels than patients without cirrhosis (26). In addition to increased proinflammatory cytokines, patients with chronic liver diseases also exhibit 
elevated levels of anti-inflammatory cytokines such as IL-1Ra, soluble TNF receptors or IL-10 (30-32). In summary, the data in liver disease suggest that the balance of pro-/anti-inflammatory cytokines may be shifted toward the proinflammatory axis.

Increased production by peripheral blood mononuclear cells: Many studies show altered spontaneous and endotoxin-induced cytokine production by peripheral blood mononuclear cells (PBMC) isolated from patients with liver disease. Whereas most studies report increased production compared with healthy controls (33), some studies suggest normal or decreased cytokine synthesis (34). These results have to be interpreted in the context that this may be due to the activation state of the isolated PBMC because it is well known that diseases associated with cytokine overproduction such as sepsis syndrome may show reduced PBMC cytokine production (35). A strong correlation has been reported between gene expression of IL-18, a potent proinflammatory cytokine, in PBMC, endotoxin plasma levels and stage of liver disease (36). Therefore, the somewhat contradictory reports with regard to cytokine production from PBMC in liver diseases most likely reflect activity of the underlying disease.

Hepatic expression of cytokines in liver diseases: Many studies using reverse transcription polymerase chain reaction, in situ hybridization or immunohistochemistry have shown hepatic expression of a wide variety of cytokines in patients with liver diseases. Most studies evaluated the expression of proinflammatory cytokines, which are enhanced in viral and nonviral liver diseases (37). Chronic hepatitis $\mathrm{C}$ infection is associated with the expression of TNF- $\alpha$ and T helper (Th)-1 cytokines, and progressive liver injury correlates with increased intrahepatic expression of Th-1-associated cytokines $(38,39)$. Chronic hepatitis B infection has been linked to enhanced expression of either Th-1 or Th-2 cytokines (40). This may also reflect the fact that some HBV antigens, such as the $\mathrm{c}$ and e antigen, induce different Th subsets (41). Data in autoimmune liver disease and primary biliary cirrhosis are more conflicting with respect to the predominance of either a Th-1 or a Th-2 cytokine pattern (42). However, all of those studies support the concept of increased intrahepatic cytokine production in liver diseases.

Impaired synthesis of cytokine-regulated molecules in liver diseases: Studies that show increased circulating levels of cytokine-regulated molecules support the concept of a consistently activated cytokine cascade in liver diseases. Increased levels of neopterin, beta-2-microglobulin, soluble IL-2 receptors and several adhesion molecules have been reported in chronic liver disease $(43,44)$. Furthermore, increased serum and urinary nitrate concentrations characterize liver cirrhosis and correlate with the extent of endotoxemia and hyperdynamic changes (45). Nitric oxide, a molecule regulated partly by the cytokine-controlled enzyme nitric oxide synthase, is centrally involved in the hemodynamic abnormalities observed in chronic liver diseases. This topic has been reviewed (46).
Alcoholic liver disease and cytokines: Alcoholic liver disease is the prototype TNF-linked liver disease (47). The involvement of TNF- $\alpha$ has been demonstrated both in acute alcoholic hepatitis and in the chronic stage of alcoholic liver disease. Alcoholic hepatitis was one of the first diseases shown to exhibit increased circulating TNF- $\alpha$ levels (48). Both plasma TNF- $\alpha$ and IL-6 levels predict decreased long term survival in severe alcoholic hepatitis $(49,50)$. Furthermore, plasma levels of both TNF and soluble TNF receptors are correlated with endotoxemia and stage of liver disease (51). A recent report suggests that alcoholic hepatitis and cirrhosis are associated with distinct patterns of chemokine expression that are likely to be important factors in determining whether a patient develops acute parenchymal inflammation or chronic septal inflammation (52).

\section{BIOLOGICAL EFFECTS OF CYTOKINES AND THEIR RELATION TO ACUTE/CHRONIC LIVER DISEASE}

Cachexia: The cachexia syndrome is characterized by anorexia, weight loss, anemia and net losses of whole body lipid and protein, and is very often found in end-stage liver disease (53). Clinical signs of protein-calorie malnutrition are seen in the majority of patients with liver cirrhosis (53). Besides malnutrition and reduced calorie intake, other factors may be of importance in cachexia. The cytokine initially held responsible for causing cachexia was $\operatorname{TNF}(1,54)$. Cachexia can be induced in mice inoculated with tumour cells carrying and expressing genes for either TNF, IL-6, ciliary neurotrophic factor, leukemia inhibitory factor and IFN- $\gamma$. More direct evidence of a role for cytokines comes from observations that cachexia in experimental animal models can be mitigated by administration of specific cytokine antagonists $(55,56)$. Leptin is another endogenous mediator involved in anorexia and cachexia. Endotoxin induces leptin mRNA in adipose tissue, an effect probably mediated by TNF, causing alterations in leptin levels as observed in liver diseases $(57,58)$. Anticytokine strategies such as thalidomide in patients with human immunodeficiency virus- or tuberculosis-associated weight loss have consistently resulted in weight gain.

Cholestasis: The topic of cholestasis has been reviewed (59). Endotoxin administration has been found to induce cholestasis in vivo (59). Administration of the proinflammatory cytokines TNF and IL-2 to humans also causes cholestasis (60). Recent studies have shown that endotoxin/cytokine-induced cholestasis is caused mainly by rapid downregulation of several transporter proteins such as the basolateral sodium-dependent bile salt transporter sodium taurocholate cotransporting polypeptide (59). Mrp2, a homologue of the multidrug resistance protein mrp1, is responsible for the excretion of multivalent anionic conjugates from the hepatocyte into the bile (61). This transporter, therefore, is an important driving force of bile formation. After endotoxin administration, a decrease in the excretion of mrp2 by $50 \%$ is observed due to redistribu- 
tion of mrp2 from the canalicular membrane to an intracellular subapical compartment (61). This decreased activity of some of the transporter genes in endotoxin-treated rats can be prevented by the administration of anti-TNF- $\alpha$ antibodies. Despite that proinflammatory cytokines are key mediators of cholestasis, it has also been established that experimental obstructive jaundice leads to subsequent formation of proinflammatory cytokines (62). Therefore, these critical mediators may not only be responsible for inflammation-associated cholestasis, but their synthesis may be even further enhanced by this condition.

Hypergammaglobulinemia: Polyclonal immunoglobulin (Ig) stimulation is a common feature of chronic liver disease. Proinflammatory cytokines such as IL-1 act as costimulating factors during activation of B cells (2). IL-6, a circulating cytokine in most advanced liver diseases, is a key cytokine with respect to B cell activation and Ig synthesis. IL-6 acts on B cells at the mRNA level and mediates the differentiation of B cells into Ig-secreting cells (63). Neutralization of IL-10 inhibits secretion of IgG, IgA and IgM by B cells activated with CD40 (64). The simultaneous blocking of both endogenous IL-10 and IL-6 inhibits twothirds of the production of the three Ig isotypes when B cells are triggered through CD40 in the presence of Staphylococcus aureus particles (64). Therefore, it seems likely that the continuous production of cytokines such as IL-6 and IL-10, as observed in chronic inflammatory diseases may contribute to hypergammaglobulinemia. Not much is known, however, about which cytokines are involved in disease-specific Ig patterns in various liver diseases.

Acute phase proteins: Acute inflammation is accompanied by changes in the concentrations of several plasma proteins known as acute phase proteins (APP) (65). The liver is thought to play a central role in limiting local and systemic inflammation. Hepatocyte-specific inhibitors of RNA and protein synthesis such as galactosamine sensitize animals to the lethal effects of endotoxin and TNF, suggesting that proteins synthesized in the liver in response to endotoxin and inflammatory cytokines somehow attenuate the biological effects of these mediators (66). The role of certain APP and their regulation have been reviewed (65). Several reports suggest that APP also exert anti-inflammatory effects (66). Hepatic fibrosis: Hepatic fibrosis is a wound-healing process that develops during chronic liver injury (67). In all circumstances of wound healing, inflammation, recruitment and local proliferation of myofibroblast-like cells, and remodelling of matrix are key components. In the liver, myofibroblast-like cells are derived from activated hepatic stellate cells. Stellate cell activation is a central feature of all forms of liver injury (67). Fibrosis reflects a loss of homeostasis between fibrogenesis and matrix degeneration. Matrix metalloproteinases, which can be activated by cytokines, and their specific inhibitors such as tissue inhibitor of metalloproteinases, are of considerable importance in this process. The initiation step of fibrosis is the activation of stellate cells by mediators such as TNF released from injured hepatocytes, neighbouring endothe- lial cells and Kupffer cells (67). Nuclear factor kappa B, a major downstream effector of TNF, is activated in many inflammatory and/or fibrotic liver diseases (68). Based on this knowledge, inhibition of nuclear factor kappa $B$ is one important target for the therapeutic blockade of early steps of fibrogenesis.

Platelet-derived growth factor is the best characterized and most potent among the proliferative factors perpetuating hepatic fibrosis (67). A large number of other cytokines, such as IL-1, endothelin-1, fibroblast growth factor and insulin-like growth factor, can drive stellate cell proliferation, although none is as potent as TGF- $\beta$. Platelet-derived growth factor and TGF- $\beta$ are regulated by proinflammatory cytokines $(67,69)$. Interestingly, IFN- $\alpha$, the most commonly used cytokine in the treatment of viral liver diseases, has been demonstrated to decrease fibrosis $(70,71)$. The underlying mechanisms are not identified but may be related to its partly anti-inflammatory activity (72).

\section{POSSIBLE THERAPEUTIC CYTOKINE-MODULATING STRATEGIES IN LIVER DISEASES}

In inflammation, IL-1 and TNF can be directly antagonized using IL-1Ra or binding proteins such as soluble receptors of IL-1 and TNF or specific antibodies. Alternatively, cytokines with anti-inflammatory properties such as IL-10 can be used to decrease IL-1 and TNF biosynthesis, increase the production of their natural antagonists and deactivate inflammatory cells such as macrophages. Because inflammation plays a crucial part in many acute and chronic liver diseases, antagonism of these specific cytokines may offer a promising new avenue of treatment.

Acute liver diseases: Antagonizing TNF with specific antibodies or soluble receptors did not show any benefit in sepsis syndrome, including in patients with sepsis-related liver failure (73). However, that such an approach could be of interest in acute liver failure cannot be ruled out. Acute liver diseases without immediate liver failure, such as alcoholic hepatitis, may be an even more appropriate target for an anticytokine approach. Alcoholic hepatitis is clearly linked to TNF; therefore, antagonism of this specific cytokine is of high clinical interest in this disease. Another approach to targeting acute liver failure could be interference with the death receptor Fas or with IL-18. HGF has been shown to prevent liver failure in various models acting as an antihepatitis cytokine. The exact mechanisms for these protective effects have not been elucidated but may involve the Fas pathway because HGF abrogates Fasinduced fulminant hepatic failure in animals (74).

The early phase of liver failure in partially hepatectomized rats induces a systemic inflammatory response syndrome triggered by circulating endotoxin because this type of liver failure can be completely prevented by the endotoxin-neutralizing protein, $\mathrm{N}$-terminal bactericidal/permeability-increasing protein (75). Although corresponding data in humans are lacking, removal of endotoxin in acute liver failure has recently been demonstrated to be of benefit 
in a small group of patients (76). Administration of the endotoxin-neutralizing bactericidal/permeability-increasing protein could modulate some endotoxin-mediated aspects of acute liver failure.

Chronic liver diseases - Antagonism of inflammation: It has been established that antagonism of TNF is beneficial in chronic inflammatory disorders such as Crohn's disease and rheumatoid arthritis (77). Therefore, similar strategies could be applied to liver diseases characterized by chronic inflammation. This is especially of relevance because, in many chronic liver diseases, inflammation precedes and/or accompanies fibrosis (10).

Antagonism of fibrosis: Fibrosis results as the net effect of chronic inflammatory and noninflammatory liver diseases. Therefore, antagonism of inflammatory cytokines alone may not be sufficient. In this situation, targeting key fibrotic cytokines, such as TGF- $\beta$, may be necessary. Several cytokines, such as the commonly used cytokine IFN- $\alpha$, exhibit antifibrogenic activity $(70,71)$. In addition, it has been shown that HGF may attenuate liver cirrhosis (78). In this study, transfection of the human HGF gene into skeletal muscles of rats induced high levels of endogenous HGF and more importantly suppressed the increase of TGF- $\beta$, suppressed fibrogenesis and led to complete resolution of fibrosis in the cirrhotic rat liver (78). Therefore, in the future, chronic liver disease may be targeted depending on the severity of inflammation with or without fibrosis by a combination of anti-inflammatory cytokines such as solu-

\section{REFERENCES}

1. Thomson A. The Cytokine Handbook. New York: Academic Press, 1998.

2. Dinarello CA. Biologic basis for interleukin-1 in disease. Blood 1996;87:2095-47.

3. Santucci L, Fiorucci S, Chiorean M, et al. Interleukin 10 reduces lethality and hepatic injury induced by lipopolysaccharide in galactosamine sensitized mice. Gastroenterology 1996;111:736-44.

4. Bruck R, Shirin H, Hershkowiz R, et al. Analysis of Arg-Gly-Asp mimetics and soluble receptor of TNF as therapeutic modalities for ConA-induced hepatitis in mice. Gut 1997;40:133-8.

5. Mizuhara H, O’Neill E, Seki N, et al. T cell activation-associated hepatic injury: mediation by tumor necrosis factors and protection by interleukin 6. J Exp Med 1994;179:1529-37.

6. Schumann J, Angermuller S, Bang R, Lohoff M, Tiegs G. Acute hepatotoxicity of Pseudomonas aeruginosa exotoxin A in mice depends on T cells and TNF. J Immunol 1998;161:5745-54.

7. Orange JS, Salazar-Mather TP, Opal SM, Biron CA. Mechanisms for virus-induced liver disease: tumor necrosis factor-mediated pathology independent of natural killer and T cells during murine cytomegalovirus infection. J Virol 1997;71:9248-58.

8. Thompson K, Maltby J, Fallowfield J, McAulay M, Millward-Sadler H, Sheron N. Interleukin-10 expression and function in experimental murine liver inflammation and fibrosis. Hepatology 1998;28:1597-106.

9. Nagata S. Apoptosis by death factor. Cell 1997;88:355-65.

10. Ogasawara J, Watanabe FR, Adachi M, et al. Lethal effect of the antiFas antibody in mice. Nature 1993;364:806-9.

11. Strand S, Hofmann WJ, Grambihler A, et al. Hepatic failure and liver cell damage in acute Wilson's disease involve CD95 (APO-1/Fas) mediated apoptosis. Nat Med 1998;4:588-93.

12. Tsutsui H, Matsui K, Kawada N, et al. IL-18 accounts for both TNFalpha- and Fas ligand-mediated hepatotoxic pathways in endotoxininduced liver injury in mice. J Immunol 1997;159:3961-7. ble TNF receptors or IL-10, and antifibrogenic and regeneration-promoting cytokines such as HGF.

\section{CONCLUSIONS}

Cytokines are key mediators in the pathophysiology of acute and chronic liver diseases, and essential molecules in hepatic regeneration and fibrosis. Although endotoxin may play the key pathogenetic role in advanced stages of liver diseases, in acute and early chronic liver disease, the specific causative agents such as hepatitis viruses may trigger the cytokine cascade. Antagonism of specific cytokines important for the regulation of inflammation and/or fibrosis may be of clinical importance in both early and late stages of the disease. Several candidate cytokines or anticytokines have been identified in the past years. Because interference with the cytokine cascade in chronic inflammatory diseases such as Crohn's disease or rheumatoid arthritis has been demonstrated to be beneficial, the next millennium will bring us to the exciting clinical challenge of testing these approaches in liver diseases.

ACKNOWLEDGEMENTS: I gratefully thank Dr CA Dinarello, Department of Infectious Diseases, University Colorado Health Sciences Center, Denver, Colorado, for critical reading and Dr A Kaser, Department of Medicine, University Hospital Innsbruck for helpful comments. This work was supported by the Austrian Science Fund (P 14641).
13. Bruccoleri A, Gallucci R, Germolec DR, et al. Induction of earlyimmediate genes by tumor necrosis factor a contribute to liver repair following chemical-induced hepatotoxicity. Hepatology 1997;25:133-41.

14. Yamada Y, Fausto N. Deficient liver regeneration after carbon tetrachloride injury in mice lacking type I but not type II tumor necrosis factor receptor. Am J Pathol 1998;152:1577-89.

15. Cressman DE, Greenbaum LE, DeAngelis RA, et al. Liver failure and defective hepatocyte regeneration in interleukin-6-deficient mice. Science 1996;274:1379-83.

16. Yoshikawa A, Kaido T, Seto S, et al. Hepatocyte growth factor promotes liver regeneration with prompt improvement of hyperbilirubinemia in hepatectomized cholestatic rats. J Surg Res 1998;78:54-9.

17. Kaido T, Yoshikawa A, Seto S, et al. Portal branch ligation with a continuous hepatocyte growth factor supply makes extensive hepatectomy possible in cirrhotic rats. Hepatology 1998;28:756-60.

18. Schaper F, Siewert E, Gomez-Lechon MJ, et al. Hepatocyte growth factor/scatter factor (HGF/SF) signals via STAT3/APRF transcription factor in human hepatoma cells and hepatocytes. FEBS Lett 1997:405:99-103.

19. Violi F, Ferro D, Basili S, et al. Association between low-grade disseminated intravascular coagulation and endotoxemia in patients with liver cirrhosis. Gastroenterology 1995;109:531-9.

20. Fukui H, Brauner B, Bode JC, Bode C. Plasma endotoxin concentrations in patients with alcoholic and non-alcoholic liver disease: reevaluation with an improved chromogenic assay. J Hepatol 1991;12:162-9.

21. Goulis J, Patch D, Burroughs AK. Bacterial infection in the pathogenesis of variceal bleeding. Lancet 1999;353:139-42.

22. Paramo JA, Sangro B, Propser F, Quiroga J, Rifon J, Rocha E. Increased concentrations of tumor necrosis factor and interleukin-6 contribute to the hemostatic abnormalities in advanced liver disease. Haemostasis 1995;25:305-11. 
23. Järveläinen $\mathrm{HA}$, Fang $\mathrm{C}$, Ingelman-Sundberg $\mathrm{M}$, Lindros $\mathrm{KO}$. Effect of chronic coadministration of endotoxin and ethanol on rat liver pathology and proinflammatory and anti-inflammatory cytokines. Hepatology 1999;29:1503-10.

24. Muto Y, Nouri-Aria KT, Meager A, Alexander GJ, Eddleston AL, Williams R. Enhanced tumour necrosis factor and interleukin-1 in fulminant hepatic failure. Lancet 1988;ii:72-4.

25. Sekiyama KD, Yoshiba M, Thomson AW. Circulating proinflammatory cytokines (IL-1 beta, TNF-alpha, and IL-6) and IL-1 receptor antagonist (IL-1Ra) in fulminant hepatic failure and acute hepatitis. Clin Exp Immunol 1994;98:71-7.

26. Tilg H, Wilmer A, Vogel W, et al. Serum levels of cytokines in chronic liver diseases. Gastroenterology 1992;103:264-74.

27. Sheron N, Lau J, Daniels H, et al. Increased production of tumour necrosis factor alpha in chronic hepatitis B virus infection. J Hepatol 1991:12:241-5.

28. Cacciarelli TV, Martinez OM, Gish RG, Villanueva JC, Krams SM. Immunoregulatory cytokines in chronic hepatitis $\mathrm{C}$ virus infection. Hepatology 1996;24:6-9.

29. Spengler U, Zachoval R, Gallati H, et al. Serum levels and in situ expression of TNF alpha and TNF alpha binding proteins in inflammatory liver diseases. Cytokine 1996;8:864-72.

30. Tilg H, Vogel W, Wiedermann CJ, et al. Circulating interleukin-1 and tumor necrosis factor antagonists in liver diseases. Hepatology 1993;18:1132-8.

31. Kakumu S, Okumura A, Ishikawa T, et al. Serum levels of IL-10, IL-15 and soluble tumor necrosis factor-alpha (TNF-alpha) receptors in type $\mathrm{C}$ chronic liver disease. Clin Exp Immunol 1997;109:458-63.

32. Reiser M, Marousis CG, Neslon DR, et al. Serum interleukin 4 and interleukin 10 levels in patients with chronic hepatitis $C$ virus infection. J Hepatol 1997;26:471-8.

33. Simpson KJ, Lukacs NW, Colletti L, Strieter RM, Kunkel SL. Cytokines and the liver. J Hepatol 1997;27:1120-32.

34. Kakumu S, Okumura A, Ishikawa T, Iwata K, Yano M, Yoshioka K. Production of interleukins 10 and 12 by peripheral blood mononuclear cells (PBMC) in chronic hepatitis $\mathrm{C}$ virus (HCV) infection. Clin Exp Immunol 1997;108:138-43.

35. Munoz C, Carlet J, Fitting C, et al. Dysregulation of in vitro cytokine production by monocytes during sepsis. J Clin Invest 1991;88:1747-54.

36. Hanck C, Manigold T, Singer MV, Rossol S. Gene expression of interleukin 18 in peripheral blood mononuclear cells of patients with liver cirrhosis reflects endotoxinemia and clinical disease activity. J Hepatol 1999;30:81. (Abst)

37. Napoli J, Bishop GA, McCaughan GW. Increased intrahepatic messenger RNA expression of interleukins 2, 6, and 8 in human cirrhosis. Gastroenterology 1994;107:789-98.

38. Napoli J, Bishop GA, McGuinness GH, Painter DM, McCaughan GW. Progressive liver injury in chronic hepatitis C infection correlates with increased intrahepatic expression of Th1-associated cytokines. Hepatology 1996;24:759-65.

39. Dumoulin FL, Bach A, Leifeld L, et al. Semiquantitative analysis of intrahepatic cytokine mRNAs in chronic hepatitis C. J Infect Dis 1997;175:681-5.

40. Shindo M, Mullin GE, Braun-Elwert L, Bergasa NV, Jones EA, James SP. Cytokine mRNA expression in the liver of patients with primary biliary cirrhosis (PBC) and chronic hepatitis B. Clin Exp Immunol 1996;105:254-9.

41. Milich DR, Schodel F, Hughes JL, Jones JE, Peterson DL. The hepatitis B virus core and e antigens elicit different Th cell subsets. J Virol 1997;71:2192-201.

42. Harada K, van de Water J, Leung PS, et al. In situ nucleic acid hybridization of cytokines in primary biliary cirrhosis: predominance of the Th1 subset. Hepatology 1997;25:791-6.

43. Wilmer A, Nölchen B, Tilg H, Pechlaner C, Judmaier G, Vogel W. Serum neopterin levels in chronic liver disease. Gut 1995;37:108-12.

44. Kaplanski G, Farnarier C, Payan MJ, Bongrand P, Durand JM. Increased levels of soluble adhesion molecules in the serum of patients with hepatitis C. Correlation with cytokine concentrations and liver inflammation and fibrosis. Dig Dis Sci 1997;42:2277-84.

45. Campillo B, Bories PN, Benvenuti C, Dupeyron C. Serum and urinary nitrate levels in liver cirrhosis: endotoxemia, renal function and hyperdynamic circulation. J Hepatol 1996;25:707-14.
46. Martin P-Y, Gines P, Schrier RW. Nitric oxide as a mediator of hemodynamic abnormalities and sodium and water retention in cirrhosis. N Engl J Med 1998;339:533-41.

47. McClain CJ, Barve S, Barve S, Deaciuc I, Hill DB. Tumor necrosis factor and alcoholic liver disease. Alcohol Clin Exp Res 1998;22(Suppl 5):248S-52S.

48. Bird GLA, Sheron N, Goka J, Alexander GJ, Williams R. Increased plasma tumor necrosis factor in severe alcoholic hepatitis. Ann Intern Med 1990;112:917-20.

49. Felver ME, Mezey E, McGuire M, et al. Plasma tumor necrosis factor alpha predicts decreased long-term survival in severe alcoholic hepatitis. Alcohol Clin Exp Res 1990;14:255-9.

50. Sheron N, Birg G, Goka J, Alexander G, Williams R. Elevated plasma interleukin- 6 and increased severity and mortality in alcoholic hepatitis. Clin Exp Immunol 1991;84:449-53.

51. Hanck C, Rossol S, Bocker U, Tokus M, Singer MV. Presence of plasma endotoxin is correlated with tumour necrosis factor receptor levels and disease activity in alcoholic cirrhosis. Alcohol Alcohol 1998;33:606-8.

52. Afford SC, Fisher NC, Neil DA, et al. Distinct patterns of chemokine expression are associated with leukocyte recruitment in alcoholic hepatitis and alcoholic cirrhosis. J Pathol 1998;186:82-9.

53. Kondrup J, Müller MJ. Energy and protein requirements of patients with chronic liver disease. J Hepatol 1997;27:239-47.

54. Vassalli P. The pathophysiology of tumor necrosis factors. Ann Rev Immunol 1992;10:411-52.

55. Ling PR, Schwartz JH, Bistrian BR. Mechanisms of host wasting induced by administration of cytokines in rats. Am J Physiol 1997;272:E333-9.

56. Haslett PA. Anticytokine approaches to the treatment of anorexia and cachexia. Semin Oncol 1998;25:53-7.

57. Berkowitz DE, Brown D, Lee KM, et al. Endotoxin-induced alteration in the expression of leptin and beta3-adrenergic receptor in adipose tissue. Am J Physiol 1998;274:E992-7.

58. McCullough AJ, Bugianesi E, Marchesini G, Kalhan SC. Genderdependent alterations in serum leptin in alcoholic cirrhosis. Gastroenterology 1998;115:947-53.

59. Trauner M, Meier PJ, Boyer JL. Molecular pathogenesis of cholestasis. N Engl J Med 1998;339:1217-27.

60. Fisher B, Keenan AM, Garra BS, et al. Interleukin-2 induces profound reversible cholestasis: a detailed analysis in treated cancer patients. J Clin Oncol 1989;12:1852-62.

61. Kubitz R, Wettstein M, Warskulat U, Häussinger D. Regulation of the multidrug resistance protein 2 in the rat liver by lipopolysaccharide and dexamethasone. Gastroenterology 1999;116:401-10.

62. Bemelmans MHA, Gouma DJ, Greve JW, et al. Cytokines tumor necrosis factor and interleukin- 6 in experimental biliary obstruction in mice. Hepatology 1992;15:1132-6.

63. Rieckmann P, Tuscano JM, Kehrl JH. Tumor necrosis factor-alpha (TNF-alpha) and interleukin-6 (IL-6) in B-lymphocyte function. Methods 1997;11:128-32.

64. Burdin N, Rousset F, Banchereau J. B-cell-derived IL-10: production and function. Methods 1997;11:98-111.

65. Gabay C, Kushner I. Acute-phase proteins and other systemic responses to inflammation. N Engl J Med 1999;340:448-54.

66. Tilg H, Dinarello CA, Mier JW. Interleukin-6 and acute phase proteins: anti-inflammatory and immunosuppressive mediators. Immunol Today 1997;18:428-32.

67. Olaso E, Friedman SL. Molecular regulation of hepatic fibrogenesis. J Hepatol 1998;29:836-47.

68. Hellerbrand C, Jobin C, Iimuro Y, Licato L, Sartot RB, Brenner DA. Inhibition of NFkappaB in activated rat hepatic stellate cells by proteasome inhibitors and an IkappaB super-repressor. Hepatology 1998;27:1285-95.

69. Kawaguchi Y, Hara M, Wright TM. Endogenous IL-1 $\alpha$ from systemic sclerosis fibroblasts induces IL-6 and PDGF-A. J Clin Invest 1999;103:1253-60.

70. Mallat A, Preaux AM, Blazejewski S, Rosenbaum J, Dhumeaux D, Mavier P. Interferon alfa and gamma inhibit proliferation and collagen synthesis of human Ito cells in culture. Hepatology 1995;21:1003-10. 
71. Fort J, Pilette C, Veal N, et al. Effects of long-term administration of interferon $\alpha$ in two models of liver fibrosis in rats. J Hepatol 1998;29:263-70.

72. Tilg H. New insights in the mechanisms of interferon-alfa: An immunoregulatory and anti-inflammatory cytokine. Gastroenterology 1997;112:1017-21.

73. Fisher CJ Jr, Agosti JM, Opal SM, et al. Treatment of septic shock with the tumor necrosis factor receptor:Fc fusion protein. The Soluble TNF Receptor Sepsis Study Group. N Engl J Med 1996;334:1697-702.

74. Kosai K, Matsumoto K, Nagat S, Tsujimoto Y, Nakamura T. Abrogation of Fas-induced fulminant hepatic failure in mice by hepatocyte growth factor. Biochem Biophys Res Commun 1998;244:683-90.
75. Boermeester MA, Houdijk AP, Meyer S, et al. Liver failure induces a systemic inflammatory response. Prevention by recombinant $\mathrm{N}$-terminal bactericidal/permeability-increasing protein. Am J Pathol 1995;147:1428-40.

76. Iwai H, Nagaki M, Naito T, et al. Removal of endotoxin and cytokines by plasma exchange in patients with acute hepatic failure. Crit Care Med 1998;26:873-6.

77. Targan SR, Hanauer SB, van Deventer SJ, et al. A short-term study of chimeric monoclonal antibody cA2 to tumor necrosis factor alpha for Crohn's disease. Crohn's Disease cA2 Study Group. N Engl J Med 1997;337:1029-35.

78. Ueki T, Kaneda Y, Tsutsui H, et al. Hepatocyte growth factor gene therapy of liver cirrhosis in rats. Nat Med 1999;5:226-30. 


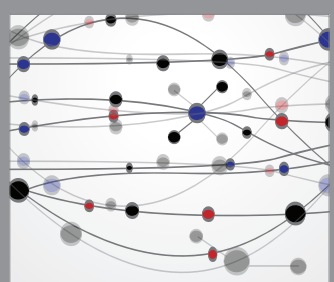

The Scientific World Journal
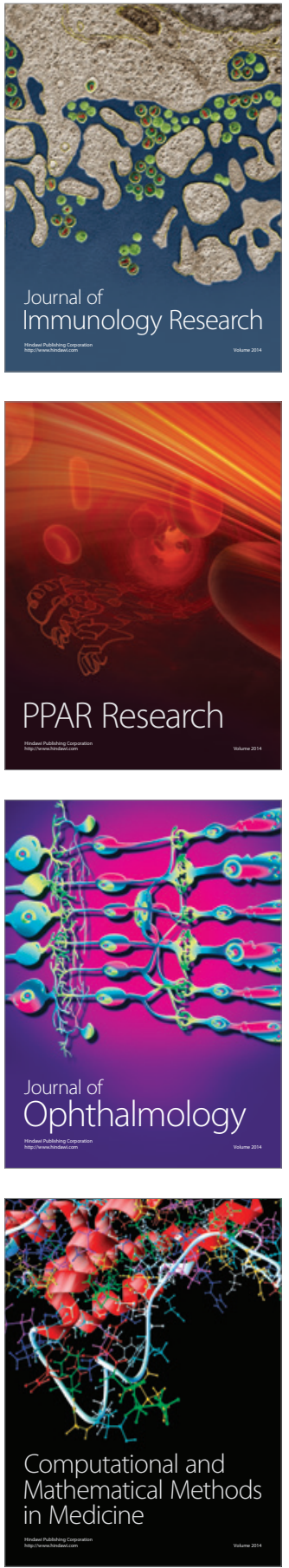

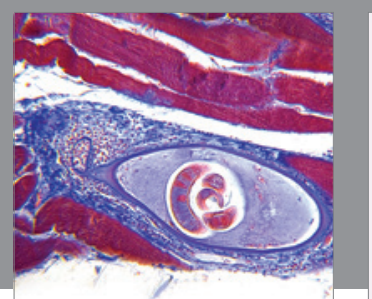

Gastroenterology Research and Practice

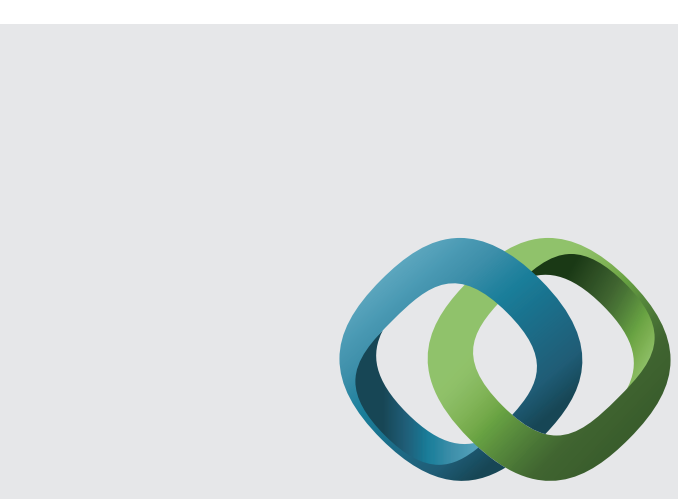

\section{Hindawi}

Submit your manuscripts at

http://www.hindawi.com
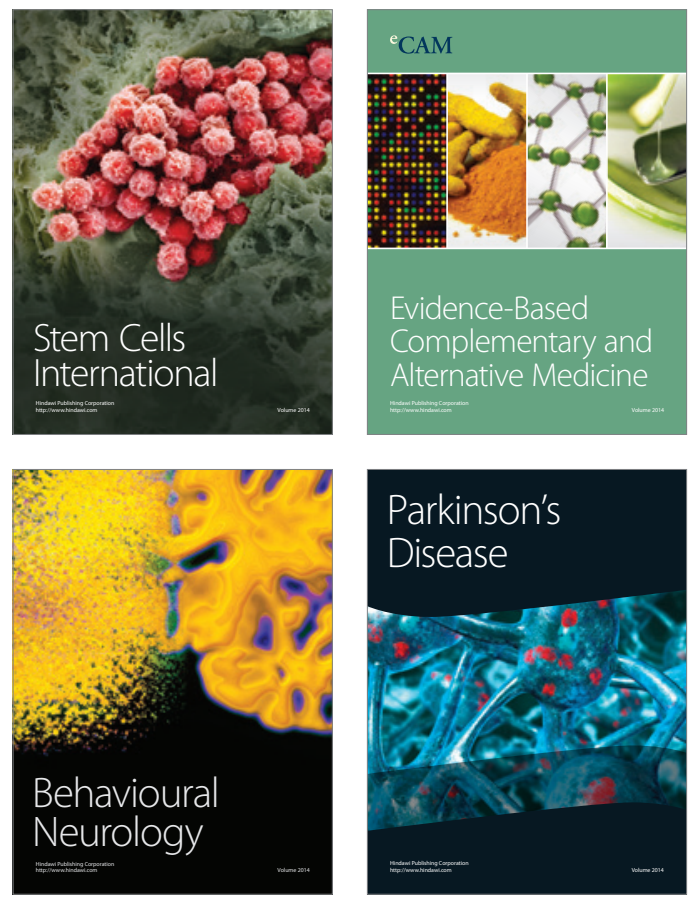
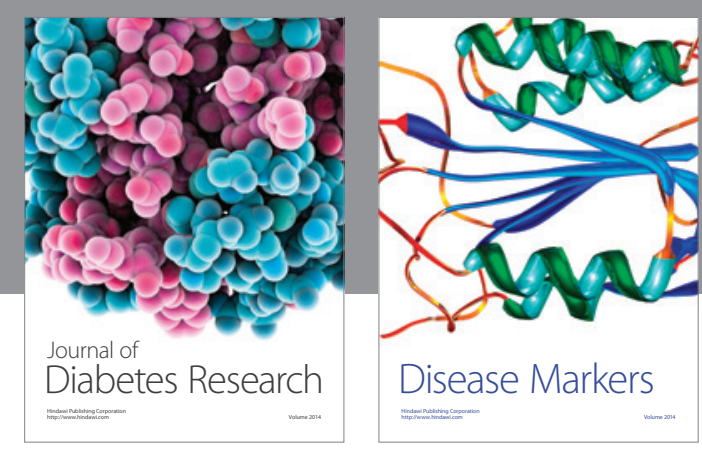

Disease Markers
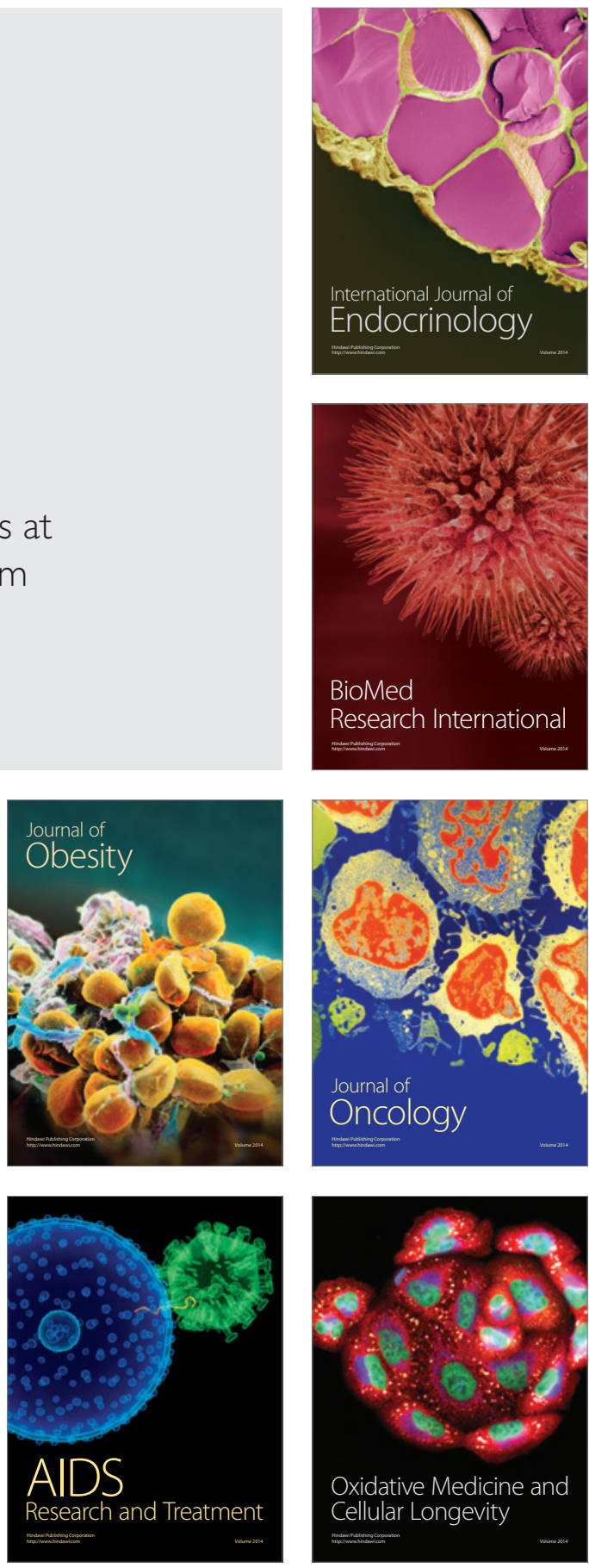